Philosophie ANTIQUE
Philosophie antique

Problèmes, Renaissances, Usages

17 | 2017

Platon et la politique

\title{
José KANY-TURPIN (trad.), Cicéron, Fins des biens et des $\operatorname{maux}$
}

Julie Giovacchini

\section{(2) OpenEdition}

\section{Journals}

Édition électronique

URL : https://journals.openedition.org/philosant/313

DOI : 10.4000/philosant.313

ISSN : 2648-2789

\section{Éditeur}

Éditions Vrin

\section{Édition imprimée}

Date de publication : 1 novembre 2017

Pagination : 220-221

ISBN : 978-2-7574-1807-9

ISSN : $1634-4561$

Référence électronique

Julie Giovacchini, « José kAny-turpin (trad.), Cicéron, Fins des biens et des maux », Philosophie antique [En ligne], 17 | 2017, mis en ligne le 01 novembre 2018, consulté le 02 décembre 2022. URL : http:// journals.openedition.org/philosant/313; DOI : https://doi.org/10.4000/philosant.313

\section{(ब) $\Theta \Theta$}

Creative Commons - Attribution - Pas d'Utilisation Commerciale - Pas de Modification 4.0 International - CC BY-NC-ND 4.0

https://creativecommons.org/licenses/by-nc-nd/4.0/ 
divinisation d'un homme eu égard à sa fonction politique; par ailleurs la place croissante accordée à l'individu qui se traduit d'ailleurs, chez les stoïciens, par une attention toute particulière au progressant. Trois aspects d'une version impériale de la piété stoïcienne peuvent être retenus. Hormis les penseurs non romains - notamment Épictète -, le mos maiorum compte et joue un rôle non négligeable dans la manière dont les stoïciens romains problématisent la piété. Dans un contexte de culte impérial, certains aspects de la piété stoïcienne ne sont pas sans assumer un rôle critique d'un point de vue politique un aspect qui nous a semblé particulièrement original dans la réflexion menée par JPC. La divinisation de l'homme appelé à « vivre comme les dieux » ici et maintenant concerne le sage, des figures morales traditionnelles (Cornutus) ou le progressant (Sénèque) mais pas le Prince - hormis peut-être chez Marc Aurèle où le culte de son daimon/genius s'accompagne d'une réflexion sur la qualité et la vertu du Prince. De même, l'A. souligne l'importance d'une forme de libertas inhérente à la piété chez Cornutus aussi bien que chez Perse. Enfin, il faudrait souligner non seulement l'importance mais surtout le sens de la référence au daimôn chez les penseurs romains, à la charnière entre une réflexion sur le progrès moral et la divinisation.

Enfin, s'il ne nie pas du tout le rôle stratégique que peut jouer la religion, chez Sénèque ou chez Marc Aurèle où elle fonctionne comme une sorte de « raccourci » dans l'ascèse morale, l'A. montre aussi qu'on ne saurait subordonner systématiquement la référence à la religion à la question morale. Et c'est une autre thèse forte défendue dans l'ouvrage. Qu'il s'agisse de Cléanthe, de Cornutus, d'Épictète ou de Marc Aurèle, il existerait, selon JPC, une dimension proprement religieuse - jusqu'alors négligée dans les études sur le stoïcisme - qui implique que l'on s'intéresse cette fois au genre des œuvres, au style et à la rhétorique mis en œuvre. Et l'A. d'ajouter que c'est là pour les stoïciens une manière d'exprimer quelque chose du divin que ne permet pas le seul discours rationnel.

L'ouvrage de JPC s'avère donc une étude précieuse pour sa richesse et sa précision qui constitue un apport majeur pour les études stö̈ciennes contemporaines. Le seul regret que l'on pourrait avoir serait l'absence de contextualisation ou de situation de l'enquête dans notre propre actualité. Mais, comme JPC le dit à propos de Cornutus, ce silence a peut-être déjà en lui-même une valeur critique.

Sandrine Alexandre

Université Paris Nanterre, IRePh

José Kany-Turpin (trad.), Cicéron, Fins des biens et des maux, Paris, Flammarion, 2016 (G. F., 1568), 340 p., ISBN 978-2-0813-8263-3.

José Kany-Turpin est depuis longtemps une des meilleures spécialistes françaises du latin philosophique classique; sa traduction du De Rerum Natura de Lucrèce, en 1993, fit date; ses récentes traductions de textes philosophiques de Sénèque (2005) et Cicéron (le De Divinatione en 2004, les Académiques en 2010) ont souligné sa parfaite maîtrise de ce corpus et de ses problématiques propres. S'attaquant au De Finibus du même Cicéron, elle relève un défi majeur. On possédait déjà en français la belle traduction intégrale de Jules Martha pour Les Belles Lettres, en 1928, complète mais quelque peu datée. On comptait également la tentative de Chantal Labre, dans les années 1990, insatisfaisante en de nombreux aspects. J. Kany-Turpin, forte de son expérience de la langue philosophique de Cicéron, a repris le dossier avec énergie et talent, et le résultat est exemplaire, à la hauteur du regain d'intérêt actuel pour ce texte (intérêt dont témoigne la parution toute récente du volume édité par Julia Annas et Gábor Betegh, Cicero’s De finibus : Philosophical Approaches, Cambridge, Cambridge University Press, 2016).

La contextualisation du texte, établie par une introduction dense et remarquable 
de clarté, offre les différents éléments biographiques et doctrinaux indispensables pour comprendre l'entreprise de Cicéron; celui-ci se propose dans le De Finibus de faire un véritable état de la question du telos et de la vie heureuse dans les différentes éthiques philosophiques des principales sectes hellénistiques, et plus particulièrement chez les épicuriens, les stoïciens et les disciples d'Antiochus - transfuge de la Nouvelle Académie dont on sait que Cicéron lui-même a suivi l'enseignement. J. Kany-Turpin fournit, dans des notes abondantes et précises, une quantité appréciable de références bibliographiques récentes qui complètent l'information qu'elle ne pouvait développer dans le cadre d'une introduction. L'accent est mis sur l'enjeu philosophique de l'ouvrage, au-delà de la simple compilation doxographique à laquelle il est encore trop souvent réduit. Le plan analytique est agréablement complété par une série de brèves notices portant sur des concepts centraux de la pensée cicéronienne : la nature, l'honestas, les catégories éthiques du bien et du devoir. Un léger regret : qu'il ne soit pas fait un sort, dans cette introduction, à la notion même de dialogue littéraire tel que Cicéron le pratique, et à sa filiation stylistique et méthodologique platonicienne - et ce, d'autant plus que la traductrice a été soucieuse, comme elle le souligne en p. 42, de rendre justice à la langue élégante et complexe de l'auteur, sans sacrifier la précision à la nécessaire « énergie » du dialogue.

Les différents choix de traduction sont expliqués de façon claire dans les notes finales de l'ouvrage, et parfois justifiés par des propositions de leçons originales - le cas est assez rare néanmoins, J. Kany-Turpin s'éloigne peu du texte établi par J. Martha, et lorsque c'est le cas les solutions qu'elle propose clarifient le texte de façon prudente et raisonnable - ainsi pour le très obscur passage de V, VI, 15 (p. 225), résolu élégamment en suivant Madvig. La traduction dans son ensemble est très fluide, précise et agréable à lire, mais ne propose pas véritablement d'innovations majeures dans la compréhension détaillée du texte. La plus grande audace réside peut-être dans le choix de traduction du titre: «Fins des biens et des maux », justifié dans l'introduction par la volonté de rappeler la double acception du terme latin finis, à la fois « limite » et « finalité ». S'appuyant sur la correspondance de Cicéron, qui désigne son propre ouvrage par l'expression Peri telon, J. Kany-Turpin suppose que le titre latin De finibus bonorum et malorum « répond d'abord à une habitude latine de préciser les termes abstraits par un complément » (p. 12). Ce point est peut-être contestable; en effet, il nous semble que le livre de Cicéron a de fait quelque peu débordé l'objectif d'un simple traité Sur la fin, dans la mesure où il a justement travaillé la question des choix éthiques réels découlant de la fixation principielle du telos. La surdétermination du titre nous semble donc quelque chose de plus qu'une simple précision : elle engage un programme philosophique spécifique qui n'est que partiellement traduit par le terme français de « fin ».

Une bibliographie clôt le livre, assez complète - et qui a l'immense mérite de proposer un choix assez important d'éditions et de traductions du texte, alors que l'absence de référence aux sources est trop souvent la faiblesse des publications philosophiques récentes. Le lecteur bénéficie également d'un index de noms propres très utile pour se repérer dans la multitude des allusions historiques et littéraires dont le texte cicéronien est truffé.

Un grand regret : alors que l'introduction p. 45 et la page de titre signalent que le texte latin traduit dans ce volume est « téléchargeable gratuitement sur le site des éditions Flammarion », nous ne pouvons que constater avec amertume l'impossibilité de trouver l'information sur le site en question.

Julie Giovacchini

CNRS - UMR 8230, Centre Jean Pépin 